\title{
Consolidating Contestation and Conflict through Community-Based Adaptation (CBA)
}

\section{-Community Based Adaptation (CBA) as a Source of Conflict in Strengthening Local Adaptive Capacity and Resilience in Semi-Arid Regions in Sub-Saharan Africa}

\author{
Sebastiaan Soeters*, Annelies Zoomers \\ Faculty of Geosciences, Universiteit Utrecht, Willem C. van Unnikgebouw, Heidelberglaan, Utrecht, The Netherlands \\ Email: *s.r.soeters@uu.nl, e.b.zoomers@uu.nl
}

How to cite this paper: Soeters, S. and Zoomers, A. (2017) Consolidating Contestation and Conflict through CommunityBased Adaptation (CBA). Journal of Geoscience and Environment Protection, 5, 174-193.

https://doi.org/10.4236/gep.2017.511013

Received: August 1, 2017

Accepted: November 19, 2017

Published: November 22, 2017

Copyright $\odot 2017$ by authors and Scientific Research Publishing Inc. This work is licensed under the Creative Commons Attribution International License (CC BY 4.0).

http://creativecommons.org/licenses/by/4.0/

\begin{abstract}
This article, based on fieldwork in Ghana, Burkina Faso and Kenya, provides an overview of different types of climate change adaptation interventions that are currently being implemented to enhance local community's adaptive capacity and resilience. We show that CBA interventions, whilst measurably successful from the interventionist perspective, are often structured to cause new scarcities, competing claims and ultimately, various forms and intensities of conflict. We conclude that, instead of targeting "communities" or other groups of "beneficiaries", the inter-connectedness of multiple (and at times competing) social groups (men and women, the elderly and youth, hunters, loggers, pastoralists and sedentary crop farmers etc.) in relation to the use and distribution of natural resources should be the point of departure for strengthening resilience and adaptive capacity.
\end{abstract}

\section{Keywords}

Climate Change Adaptation, Community-Based Adaptation, Exclusion, Conflicts, Resilience, Social Capital, Kenya, Ghana and Burkina

\section{Introduction}

Climate change is today regarded as a fundamental development issue. This is especially true in the world's most marginal areas, where even incremental climatic changes may threaten large numbers of peoples whose livelihoods are highly exposed to both sudden-onset climate shocks, such as droughts and floods, as well as slow onset changes, such as increasing temperatures and/or 
changes in annual precipitation patterns [1] [2] [3]. It is, furthermore, increasingly clear, that the success of attaining the newly-formulated Sustainable Development Goals (SDGs), will depend upon how successful developmental regions are at strengthening local adaptive capacity and resilience [4]. The fundamental importance of addressing climate change for the purposes of climate-smart development is matched by large amounts of multilateral and bilateral financing made available to intensify efforts to reduce the carbon emissions of emerging economies (mitigation) as well as to strengthen the adaptive capacity and resilience of vulnerable populations in the Global South (adaptation) [5] [6]. Whilst mitigation and adaptation efforts may, in some instances, be difficult to distinguish from one another on the ground, this article is especially concerned with the impact of a growing number of climate change projects, programs and policy frameworks financed as adaptation measures i.e. strengthening the capacity of people to adapt to changing climates. In rural contexts in the Global South, this is done in a number of concrete ways, including, but not restricted to, technical assistance to embed new sustainable farming practices, such as integrated soil fertility management and agro-forestry; community-based microfinance to enable borrowing for the diversification of income streams; the introduction of drought or flood resistant crop and seed varieties; early warning systems; new infrastructure for protection (e.g. dikes etc.) and/or providing new sources of water largely to stabilise the supply of irrigation water (e.g. ponds, dams etc.). More specifically, the article focuses upon Community-Based Adaptation (CBA), which represents a popular, bottom-up and participatory approach to strengthening adaptive capacity and resilience. CBA approaches, which have emerged to some extent as a response to top-down and technology-driven projects ${ }^{1}$, focus, as the name implies, on communities as loci of adaptation actions and tend to stress that vulnerability to climatic change is largely a result of social and economic deficits, and therefore, whilst technology transfers may well be required to address climatic changes in vulnerable regions in the Global South, adaptive capacity is largely function of a society's capacity to make informed and collective decisions in response to uncertain climatic changes.

In this article, based on in-depth field research in Ghana, Burkina Faso and Kenya $^{2}$, we focus on three case studies of CBA interventions in semi-arid and sub-humid belts in Africa (dry-season farming in northern Ghana, small-scale irrigation in southern Kenya and agro-forestry in western Burkina Faso), focusing

${ }^{1}$ Clearly, adaptation interventions are implemented in many formats, supported by different climate change and development ideologies. To date, top-down, technology transfers appear to have dominated the adaptation agenda, propped up by the "scientistic" notion that weak adaptive capacity is an outcome of changing weather patterns, and best remedied (urgently) by the introduction of new technologies and innovations. In contrast, CBAs approaches have emerged to some extent as a response to top-down tendencies.

${ }^{2}$ The cases for this article have been taken from a research project entitled Towards Inclusive Climate Change Intervention (TICCI). TICCI is part of a programme on Conflict and Cooperation over the Management of Climate Change (CCMCC), funded by the Depart for International Development (DFID) of the United Kingdom, through the Netherlands Organisation for Scientific Research (NOW-WOTRO). 
on how these solutions to adaptation deficits are also a new source of exclusion and conflict. In analysing CBA interventions, we use social capital as a lens through which to understand the impact of $\mathrm{CBA}$ on changing social relations within and between communities.

The article proceeds with a theoretical overview, followed by three case studies of CBA interventions implemented in semi-arid and sub-humid regions in Africa. After the discussion, we conclude by exploring ways forward in making climate adaptation interventions less conflictive and more inclusive, focussing upon adapting current thinking around employing social dynamics of landscapes as points of departure for future adaptation programming.

\section{The Conceptual Underpinnings of Community-Based Adaptation (CBA) Interventions}

In the context of climate policies, there is currently an increase of new programmes and projects which aim to help local communities to become less vulnerable and deal better with the adverse consequences of climate change. Focusing on the large numbers of interventions being carried out since the early 2000s, it is striking that (even though being hitherto embedded in top-down structures and discourses), there is today "a rush by climate change practitioners to be involved in Community-Based Adaptation" [7]. Whilst there is no consensus on what $\mathrm{CBA}$ is, it generally adheres to a number of criteria. Perhaps fundamentally, the CBA projects should be community-led, based upon local priorities, needs, knowledge and capacities, and involve significant emphasis on participation and participatory planning. Whilst CBAs are sometimes regarded as the antithesis of top-down technology transfer approaches to adaptation in rural, developmental contexts, CBAs do not exclude the transfer of technologies. They do however prioritise a vast array of "software", which they assume is required if technology transfers are to be successfully or meaningfully taken up (in terms of strengthening adaptive capacity), as well as inclusive.

CBAs serve as a continuation of earlier community-based development trajectories [8], which starts from the idea that a society's capacity to adapt to climatic change is contingent upon its ability to act collectively [1] which, in turn, depends upon existing rules, value and norms. According to Cannon, a necessary step for achieving collective action is strengthening relations within community-based target groups [8]. In other words, improving the networks-and strengthening social capital-are assumed to help increase the adaptive capacities of communities, and more specifically, their flexibility in dealing with both sudden-onset or incremental long-term climatic changes [9] [10] [11]. More specifically, "social capital is an essential element of adaptive capacity, because successful adaptation depends to a large extent on the capacity of a society or a community to coordinate decision making, to act collectively, and to give collective action some kind of stability by means of an institutional framework" [12]. In order to "give collective action some kind of stability", CBAs pay much attention to capacity building and/or strengthening institutional frameworks [12], 
e.g., the formation of water committees, or women's groups responsible for managing and regulating the collective action surrounding shared natural resources, often comprising of elected members from within the target community. The introduction of new institutions having direct implications for power relations within and between communities, and, more particularly the access, use and control of natural resources.

Strengthening social capital is therefore a primary ambition of CBA interventions. Despite the positivity attributed to social capital as a panacea to many developmental gaps, literature on social capital increasingly problematizes it, with several authors noting that social capital may have "perverse"3 affects [10] [13] [14]. It is for instance clear that high levels of social capital (and collective action) are required for, for instance, organised conflict and discrimination. Thinking about under which conditions social capital is perverse (resulting in conflict, exclusion and/or discrimination) is, needless to say, an important and relevant exercise in terms of interventions which seek to strengthen social capital. In order to make sense of the conditions under which social capital may have perverse effects, we deconstruct social capital, as others have done, making a distinction between "bonding" and "bridging" social capital where "bonding" social capital refers to "ties within a defined socioeconomic group" such as, for instance, an ethnically-bound community, and "bridging" social capital, which refers to "economic and other ties that are external to the group" [15] [16]. There are several other "types" of social capital, such as "linking social capital", which stresses the relations between people and governance and other regulatory institutions. Whilst this is clearly relevant for adaptation more generally, for the sake of clarity and simplicity, our conceptual model (for linking social capital reformulations by CBA interventions with conflict) focuses exclusively upon the distinction between bonding and bridging social capital.

Whilst empirically, the distinction between bonding and bridging social capital may be difficult to meaningfully distinguish, it is safe to say that development actors implementing project-based, CBA interventions in semi-arid and sub-humid regions in Africa focus largely on bonding social capital [17]. Target groups by and large belong to the same community, and share strong inter-family links, as well as ethnic and religious identities, sharing a strong sense of affiliation with norms, rules and values. Except under exceptional circumstances, levels of trust and reciprocity are strong within groups who share norms and values. Apparent homogeneity is seen to make adaptation easier since, as high levels of social capital are likely to pre-exist, organising groups for collective action is met with less resistance, than when groups are heterogeneous. Creating structures for organising for collective action is, for instance, easier when groups share family, ethnic, religious and institutional (i.e. chieftaincy) and legal (land ${ }^{3}$ For a summary of the negative impacts of social capital see Alejandro Portes' text, The Origins and Applications of Social Capital in Modern Sociology. Portes, as others have done, challenging the uptake of social capital by development practitioners as "a cure-all for the maladies affecting society at home and abroad", illustrates how conformity (as a result of strong norms and sanctions within household/communities i.e. social capital) may also have negative impacts for developmental processes. 


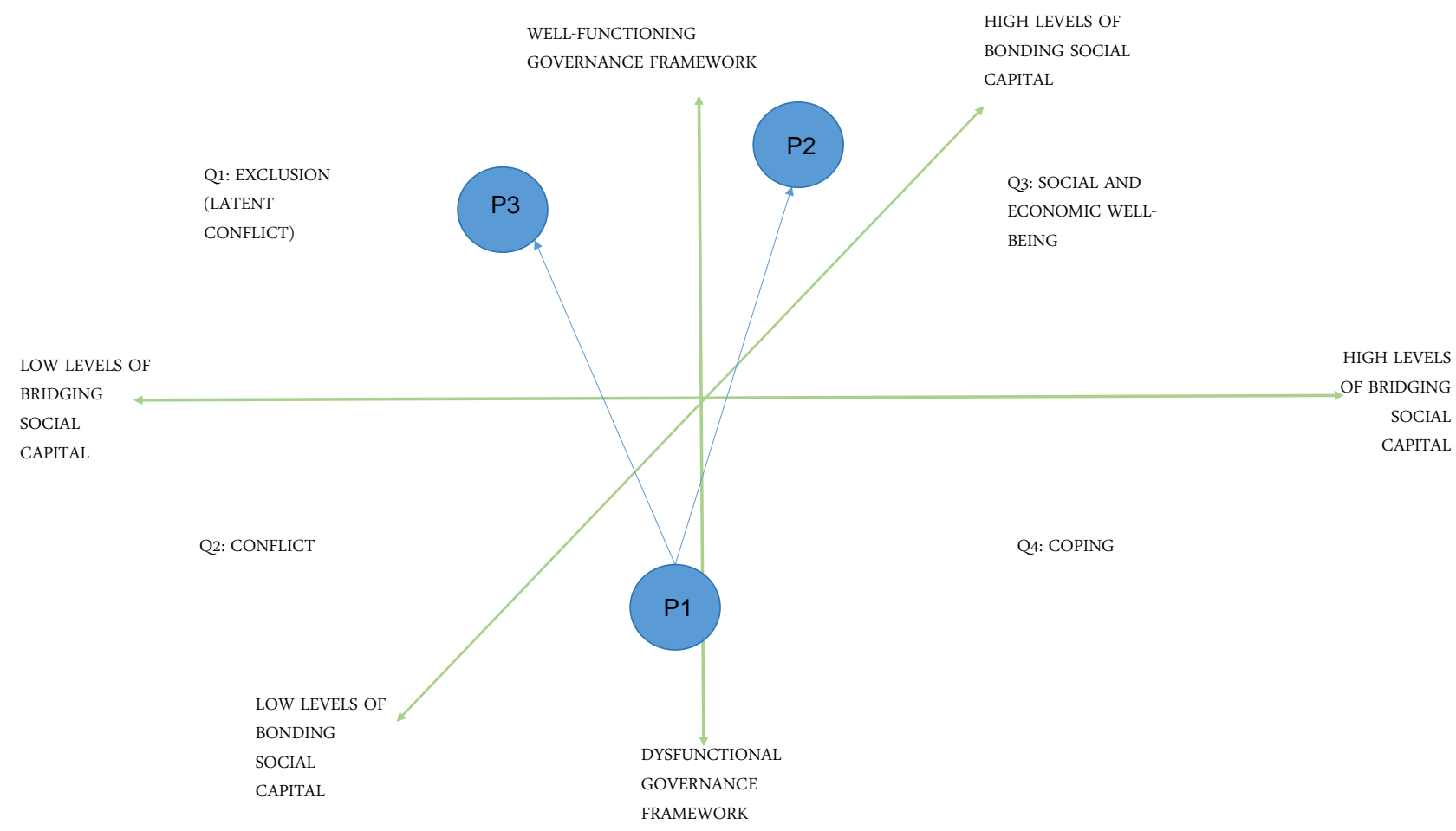

Figure 1. The interplay of bonding social capital and bridging social capital in the context of adaptation interventions. Adapted from Narayan and Woolcock, 2000.

${ }^{4}$ Narayan and Woolcock argue that under conditions of good governance and high levels of bridging social capital, there is a synergy between state and society/community, and economic prosperity and social order are more likely to occur because there is a higher level of institutional trust. In contrast, when a society's bridging social capital disintegrates social groups disconnect from one another, often leaving the more powerful groups to dominate the state to the exclusion of other groups (Woolcock \& Narayan, 2000). 
toring committees, facilitating (climate) information distribution structures and perhaps, participatory structures of inclusive management of new technologies, such as water pumps and irrigation systems, and ensuring access to certified seeds. Targeted communities (or "beneficiaries") are helped to benefit from a series of advantages in using natural resources (land, rivers, other water bodies, such as dugouts or dams, crop residues etc.), which they may well share with neighbouring communities and/or other social groups, such as hunters, foragers, pastoralists etc. If the CBA is successful, bonding social capital is further strengthened, and the quality of governance is improved. In this article, we explore the implications of different types of CBA interventions for bonding capital (e.g., shift to increased internal cohesion, benefit sharing within the group), while analysing the direct and indirect effects for external relations, and more particularly, the availability and functioning of bridging social capital. Focusing on three case studies of $\mathrm{CBA}$ interventions which are aimed at strengthening "bonding capital", what are the implications for the adaptive capacity (inclusion, exclusion) and resilience of non-target-groups? How to prevent that developments go in the wrong direction (P3, instead of P2)?

\section{Three Case Studies in Dryland Belts in Sub-Saharan Africa}

In dryland regions of sub-Saharan Africa, scarcity and unpredictable environmental and ecologically conditions, including extreme weather, have had a profound effect on shaping local livelihood patterns and portfolios [18]. Notably, livelihood patterns and portfolios are designed to manage environmental risks and survive adverse circumstances. As a result, households often engage in a variety of activities, hedging risks over time, space and different assets, which, in turn, results in high-levels of livelihood variations, and pronounced differentiation in use of, and access to natural resources. Importantly, the same natural resource, make be exploited in different ways, by different social groups. Landless youth and women may use bush land for hunting, and rivers for fishing, whilst farmers seek to exploit that land and that river for crop-farming and irrigation. Simultaneously, nomadic and semi-nomadic pastoralists may seek to exploit the water as a drinking resource for their cattle, and the bush land, as pasture and refuge. These groups not only make use of natural resources in different (competing) ways, they may well have very different definitions of sustainability, intensification, resilience and adaptive capacity, which CBAs attempt to manipulate in order to enable target groups to better manage climatic changes. Socioeconomic groups (gender, livelihood, ethnic, religious, generational etc.) are, as a result, connected through delicately-balanced, competing claims within and between households, livelihoods and communities. This fact has been confirmed by livelihood studies popular during the 1990s [19] [20] [21]. In such contexts, the permutations of bridging and bonding social capital in terms of sharing and competing for natural resources are, needless to say, highly complex, and reformulating existing structures of social capital may well have serious, and 
far-reaching implications.

Despite this complexity, CBAs in dryland regions in Africa ordinarily employ singular perspectives, linking single natural resources to single livelihoods/communities/gender/ethnicity etc. This mode of operation represents efforts to make complex realities more legible in order to arrive at outcomes related to strengthening adaptive capacity, but also, for instance, for purposes of measuring, monitoring and evaluation, a requirement whose importance should not be understated. Furthermore, in conducting research for this article, it is clear that in some cases, CBA interventions do recognise that one natural resource may be used by more than one livelihood. By and large, however, instead of focussing on the inter-relational and benefit-sharing dynamics of different livelihoods around, or competing uses of, the natural resources which are to be manipulated (made more effective, efficient or used more intensively in a sustainable manner), CBA interventions tend to treat those livelihoods as separate, or otherwise unconnected and the problem of singularity largely persists.

With this in mind, we present three case studies, each based on in-depth field work and data collection carried out between 2014 and 2016.

The first case study is an adaptation intervention in northern Ghana which sought to strengthen the adaptive capacity of a single livelihood, dedicating a natural resource (a stretch of low-lying, largely unfarmed land) to one livelihood (dry-season watermelon farming), with no regard for competing claims over land emanating from other livelihoods, notably pastoralism, equally dependent upon that same tract of land for pasture and water. The second case study, from southern Kenya, focusses upon an adaptation intervention which acknowledges the existence of two user groups of a new developed water infrastructure (farming and pastoralism), but makes no effort to strengthen the interconnectedness of those livelihoods, socially, economically, ecologically or indeed, in terms of governance structures. The third case focuses upon a forestry intervention in Burkina Faso. Whilst a committee has been established to manage forest resources in a participatory way (recognising a plethora of forest resource users), the loggers association dominates decision-making, and largely dictates how forest resources are used at the expense of both local fishermen, as well as pastoral communities, who have different (competing) definitions of "sustainable forest management". We discuss each of the case studies in terms of reformulations of social capital and the potential for new dynamics of conflict.

\section{Methodology and Selection of Cases}

The cases were selected based on a number of criteria. Each of the cases selected was required to be located in African drylands. African drylands only pose a series of unique climate change challenges (climate change "hot spots"). African drylands are also the focus of increasingly large sums of financing earmarked of strengthening the adaptive capacity and resilience of vulnerable groups. Each case quite obviously had to focus upon a defined adaptation intervention. Prior 
to the selection of cases, analyses of emerging adaptation regimes in Burkina Faso, (northern) Ghana and (southern) Kenya were conducted to identify adaptation the major contours and foci of adaption discourse and practice in each of the sub-regions. In Burkina Faso, reforestation as a means of combatting desertification was identified as a dominant adaptation discourse and practice; in northern Ghana, dry-season farming has been identified as a way of reducing exposure to rainfall variability (since it depends on irrigation, rather than directly in rainfall), as well as a means for diversifying income (and livelihoods); in (southern) Kenya, building irrigation and pastoral infrastructure in the form of water sources, has emerged as an important adaptation rhetoric in the context of pastoral sedentarisation and group ranches.

Having identified comparable case studies, we set out a cross-case methodology for the purposes of comparability, focussed on a combination of ethnographic methods (in depth interviews, participant observation and Focussed Group Discussions (FDGs), coupled with an extensive survey (N > 100 in each of the cases). We developed the survey around social capital, seeking to understand how different adaptation interventions implemented in African drylands changed relations within and/or between communities (target beneficiaries vs non-beneficiaries). We built the survey around indicators for the central tenants of social capital i.e. levels of trust, reciprocity, collective action, association, flows of information and communication, social cohesion and inclusion and empowerment and political action. We used previously developed surveys by Grootaert et al. loosely as a point of departure for developing our own survey [22]. Surveys were slightly amended across the case studies to allow for contextual appropriateness. Data from the survey was not only used to triangulate findings from ethnographic methods, it was also intended to increase comparability across cases, in the Burkina Faso case study (Tiogo Forest Reserve).

Finally, in each case study, Focus Group Discussion (FDG) were held with relevant groups. In most instances, beneficiaries were isolated from non-beneficiaries, in separate FDGs, although in some instances FGDs were held containing both groups. The combination of in depth interviews with key informants, FGDs, participant observation and an extensive survey, enabled both a certain level of depth in research findings, as well as a level of confidence for generalising findings regarding the impact of adaption interventions on inter-and intracommunity relations to a broader level.

Case study 1: The commercialisation of dry-season watermelon farming in northern Ghana: One natural resource, one user group

In 2010, a prominent International Non-Governmental Organisation (INGO) implemented an adaptation intervention in number of communities in northern Ghana. The project sought to strengthen the local adaptive capacity of targeted communities. Whilst the Community-Based Adaptation (CBA) project was designed to be highly participatory, and thus have different foci and emphasis in each of the communities, the basic premise across the communities was to fa- 
cilitate the establishment of a community-based micro-finance system which was to help people to diversify income and become less dependent on rain-fed farming. This coupled with access to new climate information (daily, as well as seasonal forecasts) was to ensure that people were equipped to make informed decisions (and actions) manage uncertain climate changes. Group members who made regular payments into the facility were, subject to various conditions stipulated in group constitutions, able to take loans from the facility. This would provide a reliable source of financing for group members, allowing them to timeously buy inputs for farming, pay school fees and medical insurance, buy food during the lean season, and a number of other drivers of adaptive capacity and resilience.

One of the target communities was Farfar, a rural, Bimoba ${ }^{5}$ community 15 kilometres south of the town of Garu, the capital of the Garu-Tempane district in Ghana's Upper East Region (UER). In Farfar, access to finance through the community based micro-finance facility was coupled with a drive to commercialise dry-season watermelon farming on a low lying tract of land located at the base of the Gambaga escarpment, 7 kilometres south of the community centre. This commercialisation had been indicated as a high priority in the Community Adaptation Action Plan (CAAP), which was created with a heavy emphasis on participation at the start of the project. This type of prioritisation is fundamental to Community-Based Adaptation (CBA), since CBA is premised on the assumption that environmental knowledge, vulnerability and resilience to climate impacts are embedded in societies and cultures, and suggests therefore that the focus of adaptation interventions needs to be on empowering and supporting communities to take action based on their own decision-making processes [24]. As a result a number of generators, water pumps and irrigation hoses were provided by the implementing INGO, and access to certified seed was established through local implementing partners. The water-pumps and generators are communally owned, and rules have been established for use and maintenance. The combination of access to finance and the commercialisation of dry-season watermelon farming proved to be extremely successful; a recent survey indicated that 74 percent of male members of the community-based micro-finance facility primarily took loans to finance expensive inputs for dry-season watermelon farming [25]. Commercial, dry-season watermelon farming turned out to be highly lucrative, and increasingly land along the river was transformed from "bush", with the odd youth farming some rice or onions on a very small scale during school holidays, into a professional, and highly commercial, mono-cropped, dry-season watermelon farming landscape. Today, all the available land able to yield watermelon during the dry-season is under the cultivation of watermelon during the dry-season, a total of nearly 400 acres. A project committee made up of democratically elected members from Farfar monitors the project, and com-

${ }^{5}$ The Bimoba are one of several ethnic groups in the UER. The Bimoba number over 100,000, of which approximately half reside in the UER [23]. 
municates any issues which may arise with the implementing actors.

From the project's point of view, the impacts upon the target community, Farfar's watermelon farmers, have clearly been very positive, with obvious signs that community members are not only wealthier (increase in the asset base), but are also using proceeds from dry-season watermelon farming to increasingly diversify livelihoods into, for instance, small-scale transportation (diversification). Zooming out, however, it is becomes visible that the sudden uptake of lucrative dry-season watermelon farming, created through the implementation of new community structures and other asses of the CBA, has also resulted in increasing conflicts between the watermelon farmers and nomadic and semi-nomadic pastoralists. These pastoralists belong largely to the Fulani ethnicity (in contrast to the farmers, who, as noted, are Bimoba), a largely Muslim ethnic group specialised in pastoralism, and spread across West and Central Africa. In West Africa, they customarily move large herds of cattle southwards from the Sahelian regions in Burkina Faso, Niger and Mali, into Ghana (and other coastal countries), in search of greener pastures and water during the dry-season, when the Sahel itself can no longer sustain their cattle. The "bush" which today has made way for commercial watermelon farming, provided in the past, refuge, and excellent pasture, being also situated adjacent to an otherwise fairly inaccessible stretch of perennial river. Whilst Farmer-Fulani conflicts are not at all new, they are new in terms of this tract of land, and according to both farmers and Fulani, such conflicts are increasing, both in frequency and intensity. Quarrels between farmers and Fulani are especially frequent during the dry-season, between November and April, when cattle are prone to destroying watermelon harvests in search of pasture and water, sometimes spilling over into violent confrontations. Some years are worse than others, depending on the number of Fulani who come to the area, but farmers interviewed for this study noted with unanimity that clashes with Fulani were on the increase. Increasingly farmers carry arms to their farms and sleep on their farms, since Fulani often move their cattle during the cooler nights. When asked what farmers saw as the major threat to watermelon farming, many noted "Fulani" [26]. One watermelon farmer noted, "by March, during the dry-season, this place is flooded with Fulani” [26].

Clearly, relations between farmers is strengthened through sharing of resources (such as water pumps and generators), sharing of knowledge and information, such as appropriate seed varieties and farming practices, as well through arrangements for communal labour during the harvesting of watermelon (they are difficult to carry, and the loading bays may be several hundred metres away). In other words, bonding social has been infinitely strengthened, as too has the adaptive capacity of watermelon farmers, as well as Farfar as a whole. Simultaneously, relations with Fulani pastoralists have broken down. The risk of conflict is notably higher than prior to the sudden uptake of dry-season watermelon farming, and there are no apparent efforts to reconcile pastoral and farming livelihoods. The strategy of farmers (encouraged also by the rhetoric of the local 
assemblymen) is to "sack Fulani from the area".

Case study 2: Introducing irrigation in pastoral landscapes in Narok county, Kenya: One natural resource, two user groups.

Maji Moto is a Maasai group ranch, located $42 \mathrm{~km}$ south-west of Narok, the county capital of Narok County, which lies to the south-west of Nairobi. Maji Moto is home to around 11,000 people, the overwhelming majority of whom continue to depend upon pastoral livelihoods systems for survival. The group ranch is a product of the by-now well-documented push by both colonial and post-colonial regimes to semi-sendentarize Maasai pastoralists in order to modernise the agricultural sector, better integrate Maasai livelihoods into the national economy, enable access by otherwise nomadic Maasai to services such as health care and education and preserve land for commercialised wildlife conservation [27]. Like other Kenyan group ranches, despite covering an area of 500 $\mathrm{km}^{2}$, the creation of the Maji Moto group ranch has limited the mobility of pastoralists, breaking down both commercial trade linkages, as well as limiting the capacity of pastoralists to deal with harsh environments, a dual assault on local food security. Following the formation of the group ranch in 1960s, missionaries developed Maji Moto's only perennial water source, a hot spring, in order to provide water largely for domestic use at the settlement of Mokondani [28]. Except for two Kikuyu settlers, who apparently had started small-scale garden cultivation close to the hot spring, the primary purpose of the new water infrastructure was to provide water for the missions and schools, and later, for households who could afford to pay for the pipes. In the 1990s, a local politician, lobbied by residents of Maji Moto, expanded the infrastructure to form two dams, a large dam upstream to produce pressure, and a smaller dam, downstream, to collect run off during heavy rains. The dams were intended both as a source of drinking water for pastoralist cattle herds, as well as to irrigate a growing number of small farms, taking their lead from the Kikuyu pioneers, developing in close proximity to the water source [28]. A furrow irrigation system was developed by the residents, with canals being dug several hundred metres down-stream to enable more parcel owners to access irrigation water for farming. By the early 2000s, the dam had fallen into disrepair, and in 2006, upon the initiative of a grassroots Civil Society Organisation (CSO), the Global Environment Facility's (GEF), through its Small Grants Program (SGP) funded the reconstruction and expansion of the original dam in order to strengthen local adaptive capacity in the face of rising temperatures and, as a result, a reduction in the availability of ground water [29].

From the 1990s, the privatisation or individualisation of land became increasingly formalised, and gathered momentum. This process (the privatisation or individualisation of previously common-pooled land within group ranches in Kenya) has largely been attributed to bottom-up forces seeking to protect land against large-scale acquisition by outsiders [30]. Whilst this may be true in part, the privatisation of land was also the final phase of a "sedentarisation chain-reaction", resulting from the difficulty of maintaining nomadic pastoralist 
livelihoods within the group ranch system. The chain reaction, which was sparked originally through the formation of the group ranch resulting in mobility limitations, initiated a need for permanent water sources, which in turn created a push for land privatisation for farming. In Maji Moto, the uptake of sedentary livelihoods clustered around the dam, even after the completion of the reconstruction of the dam, is fairly limited in scope (due to limitations of the irrigation system), but it is also highly uneven in terms of how benefits are shared; 217 of the privatised parcels have (differentiated) access to irrigation infrastructure from the dam, from which 1500 people (taking an average household size of 7) of the total 11,000, draw livelihoods [31]. Despite this minority, infrastructure (including governance infrastructure) around the dam is geared towards irrigation. In an attempt to strengthen governance, as is often the case with CBAs, a Water Committee has been established, mandated with regulating the use of water for irrigation for farming. Not only does the Water Committee have the authority to decide for which purposes the water can be used and during which periods of the year, but also, which plots have access to water, at which time of the day, and for how long. One must partake in farming, making use of the irrigation system, in order to serve on the Water Committee. Purely pastoralist water users, despite initially recognised as legitimate water users, are not included in, and do not feel particularly heard by, the Water Committee [Gartner 2015]. It is against the rules of the Water Committee to irrigate land for fodder for cattle. In a 2016 study on new forms of conflict and/or cooperation resulting from the reconstruction of the dam, Weesie notes that both pastoralists and agropastoralists agree that the dam has increased the supply of water in Maji Moto. Despite this, pastoralists complain that the increasing use of privately-owned water pumps by wealthy individual for irrigation, drains the dam, especially during dry months, leaving no drinking water, for amongst other things, drinking water for cattle [31]. Pastoralists complain further that the geography of the dams (a rocky hill makes it accessible only from one side, the same side where the new farms are located), coupled with the privatisation of land parcels and the intensive farming which it has facilitated, makes it difficult for them to access the dams with large herds. They are, as a result, often forced to scavenge for water in the Maji Moto periphery, where water sources are not perennial, and also increasingly located on privately-owned land, resulting in new, relative, and intra-community scarcities. On the other hand, those using the water for irrigating their farms, complain that cattle and ruminants are a source of destruction, both to the dam itself, as well as well as the furrow irrigation system [31]. Farmers also complained that cattle urinate in the water, increasing the acidity of water, which in turns damages crops upon irrigation [28].

Unlike the case of dry-season watermelon farming in Ghana, the dam at Mokondani in the Maji Moto group ranch sought to cater for two livelihoods, recognising that water was required both by those fortunate enough to have obtained land close to the dams and therefore able to use irrigation for farming as well as by pastoralists, the backbone of traditional Maasai livelihoods, who required 
a reliable source of drinking water for their herds, especially after the formation of the group ranch had limited the potential for mobile solutions to water shortages. The dams reconstructed after 2006, in the context of other changes to the distribution of natural resources i.e. privatisation of land, have fundamentally altered relations between farming and pastoral livelihoods around natural resource use [31]. Newly-formed governance structures, such as the Water Committee, are mandated for managing water for irrigation, having only a very small role in terms of access to drinking water for cattle. No effort has been made to create cohesion between the structures responsible for managing water on the one hand, and those managing land privatisation, or access routes, on the other (bridging social capital). The result in this instance is the relative exclusion of pastoral livelihoods from new abundances of water. Using a series of social capital Weesie shows that levels of trust and cooperation between farming and pastoralist actors has decreased [31].

Case study 3: Community forest management in Burkina Faso's Tiogo forest reserve: One natural resource, multiple user groups.

The Tiogo forest reserve in Burkina Faso has been subjected to several interventionist regimes, straddling colonial and post-colonial eras. Early attention (1920s) to Burkina Faso's forests regarded them primarily as sanctuaries for wildlife. There was little or no recognition of the importance of the forest for local communities, who were seen to be a primary driver of deforestation and degradation, and as a result, policies were designed and implemented to protect forests not for local communities' dependent upon the forest, but rather from them [32]. As a result, according to Wardell and Reenburg, forest reserves came to be locally referred to as "the white man's forest", pointing to land alienation and user restrictions [33]. Following independence during the 1960's Burkina Faso's forests came to be seen, through timber, as a source of much-desired, state-facilitated, economic growth and development. However, following the Sahelian drought of the 1970s and 1980s forest discourses in Burkina Faso focussed increasingly on environmental and climatic crises, and especially as a means of averting desertification [32]. Preserving forests emerged as a priority, but, aside from loggers, rarely with any meaningful attention to the multitude of livelihoods dependent upon forests. Loggers, the primary drivers of deforestation, were targeted. The central question of efforts at maintaining forests and reforestation was how to regulate logging in such a way that timber could continue to be exploited, but regulated so as not to deplete forests. In the Tiogo forest reserve, this type of thinking manifested itself through a project implemented in the 1980s, funded by, amongst others, the United Nations. A Loggers Association was established, and feedback mechanism created, whereby some of the proceeds generated through the sale of timber was used to plant new trees. Critics noted that the project largely succeeded in establishing a reliable supply of fuel wood for the regional capital, Koudougou, without having any meaningful effect on those dependent upon the forest, including loggers [33].

Following the 1992 Rio Earth Summit, as elsewhere, users of forest resources 
took up a central position in efforts to preserve and rehabilitate forests in Burkina Faso. In 1993, Burkina Faso's government re-emphasised participatory management of protected forests and signed contracts with communities living close to forests. "The aim of the new approach was to improve agricultural, forest and pasture resources, help the forests regenerate and reduce poverty" [34]. This community focus has fed into emerging climate change regimes, which continues to stress the importance of forests in slowing desertification, but also, the central role played by communities who exploit the forest and the potential to alleviate poverty through forest preservation. Burkina Faso will tap $\$ 30$ million in grants, and is expected to leverage at least an additional $\$ 13$ million in resources from the government and other donor governments, to improve the governance of the country's forests and limit forest loss and degradation in both state-owned and community-owned forests [34]. In the dual ambition of limiting forest loss and alleviating poverty, it was recognised that loggers alone in no way represented the plethora of livelihoods dependent upon the Tiogo forest. As result, in 2015, the Loggers Association was replaced by the Forest Management Committee (Comité de Gestion Forestière-CGF), in order to represent and foster cooperation between amultitude of forest user groups.

In a 2016 study of the Tiogo Forest Reserve, Cosijnse assesses in how far the shift from a focus on loggers alone, to a more holistic understanding of forest user groups has changed levels of inclusion and/or participation in the management of the Tiogo forest [32]. In doing so, she focuses on three different users of the forest reserve, namely, fishermen, loggers and pastoralists. These different livelihood correspond roughly with three distinct communities, respectively, Tiogo-Maouhoun, Tiogo Village and the Fulani Settlement. The study found that climate change is perceived as equally tangible and threatening to each of the livelihoods, and each of them also indicated that they have generally become increasingly dependent on assets retrieved from the forest area [32]. In terms of forest resources, respondents from Tiogo Village attach the greatest value to wood (for making charcoal and/or selling fuel wood) and medicinal leaves/roots extracted from the forest area, those from Tiogo-Mouhoun mainly exploited the forest area for their fishing activities (the Mouhoun river runs through the forest), whilst the Fulani mainly rely on the forest for pasture for their cattle. Since no farming is permitted within the reserve, the forest allows cattle to graze without the threat of destroying crops.

Despite the formation of a more inclusive CGF, replacing the Loggers Union, with the intention of including more livelihoods in the management of the forest, the Burkina Faso case study found that Fulani pastoralists, fishermen and other minority forest user groups continue to be excluded from decision-making processes regarding forest management. The CGF is dominated by the same leaders who ruled the Logger's Union (the chairman of the Logger's Union is now the Chairman of the CGF). The CGF has, as a result, not fostered more cooperation between forest user groups, increased participation or benefit-sharing, as was the intention. Instead, as a result of momentums of dominance (and a 
lack of attention to those momentums in the establishment of the CGF), lines between insiders and outsiders, or those with and without control over their own access and use of the Tiogo Forest Reserve persist (ibid.).

\section{Discussion}

This article sets out to answer two inter-related questions. Firstly, what is the impact of CBAs on local formations of social capital? And secondly, how do new formations of social capital, shaped by CBAs, relate to conflict?

According to the adherents of CBA, this approach will help to make communities more resilient: by strengthening structures (decision-making, innovation, access to information, ability to operationalise information, access to services etc.), communities will be empowered to act and react to ever-changing and uncertain conditions (which is considered more important than top-down interventions). Improving the processes of deliberation is considered more important than one-off increase in the asset base. Strengthening local institutions, increasing access to information and other resources, as well as stimulating collective action, such as facilitating the creation of agricultural by-laws, the distribution of information, lobbying local government for extension and other services and/or the diffusion of new innovations are considered crucial elements for making communities adaptive and resilient. Thus, in line with Adger's by now famous assertion that "a society's adaptive capacity is a function of its capacity to act collectively" [1], CBA interventions are assumed, implicitly or explicitly, to rely upon and seek to strengthen various forms of social capital (upon which collective action depends). Social capital, for instance, is required for the creation of legitimate by-laws for sustainable natural resource use and accepted sanctions for non-compliance, as well as for the diffusion of new (agricultural) technologies and innovations through communities as well as other collective actions, such as lobbying local government for extension and other services, such as dams and dugouts.

In spite of practitioners very much focusing on the beneficial effects of social capital, our results confirm that social capital can equally have "perverse" effects [10] [13] [14]. Whilst social capital relations may indeed be "productive", high levels of social capital (in one group) are also required for conflict, exclusion and marginalisation, including, for instance, consolidating uneven gender dynamics. Sustaining unequal power relations or, organising for the purpose of conflict, requires strong relations built upon shared ideas, identities, norms, values, trust and solidarity i.e. social capital. Strengthening social capital on its own, as CBAs aim to do, therefore-and this is indeed central to this article-may have perverse affects. As a result, understanding how to generate productive social capital, versus the type of approaches that generate perverse social capital, is a crucial question, especially as the popularity of CBA approaches continues to grow, and the roll-out of such interventions intensifies.

As the three case studies demonstrate, CBA often move away from P2 in the direction of P3 (see Figure 1), due to the fact that in an attempt to strengthen 
social capital within groups, CBAs drive a wedge between beneficiaries (usually sedentary farmers) and non-beneficiaries (user groups who are not the target of interventions, but are affected nonetheless), which in turn has implications for conflict. In each of the cases, we see that one group is better organised, and has stronger institutional structures and affiliation, as a result of activities and actions undertaken as part of the CBA. Such new structural assets are then employed to legitimise the use of natural resources in a specific way (land for crop farming, water for irrigation etc.) at the expense of other potential uses (pasture, for hunting, fishing etc.). This legitimisation works to exclude groups who compete for the same natural resources, but for different purposes and therefore, with different definitions of sustainability, intensification and resilience (in relation that specific natural resources). This is true even where more than one livelihood is considered, as is the case in both the Kenya and Burkina Faso cases, albeit for different reasons. This outcome, whilst it may be well be "unintended", is not incidental. Instead, as the case studies reveal, it is an outcome of the manner in which adaptation programming works, focussed as it is, on strengthening social relations within target groups, and tying access to the benefits of the intervention to belonging to that group. In doing so, CBAs ignore complex relational dynamics, momentums and trajectories around the use and distribution of natural resources.

\section{Conclusion: Making Adaptation Interventions More Inclusive and Less Conflictive}

The paper has illustrated how, in their current form, CBA interventions aimed at communities by and large simplify complex realities in terms of the use of natural resources in semi-arid and sub-humid belts in Africa. In doing so, they may well serve as a source of new dynamics of conflict. Crucially, overcoming community-bias is essential if such projects are to maintain legitimacy as a model for development. In order to do so, a shift in focus from target groups, to relationships regarding (competing) use of and access to natural resources is required. In other words, adaptation interventions which alter natural resource use patterns, should take as their point of departure the complex set of relations which exist around natural resource access and use, rather than communities who's (competing) claim to natural resource use is legitimised at the expense of other claims through the backing of an adaptation intervention (or indeed another development action).

Adaptation interventions should begin with questions of how to strengthen economic, social, ecological and political relations between multiple natural resource user groups (often with competing claims). Taking this as a point of departure produces different types of results, than might be arrived at when taking communities as points of departure. Finding ways to integrate different livelihoods becomes the highest priority. Where this is not possible (benefit sharing) adaptation interventions might seek to introduce mechanisms to redistribute the benefits of adaptation interventions more equally, in order to compensate 
non-beneficiaries who are negatively affected by the gains made by beneficiaries as a result of adaptation interventions. This may be in financial in nature, but does not have to be. Where farming and pastoralist livelihoods exist, for instance, more systematic efforts might be made to create structures whereby manure from cattle is exchanged for access to pasture and/or water. Each context will offer different potential for strengthening interconnectedness between usergroups in terms of natural resource use but, importantly, such a focus changes the types of actions which might be considered for adaptation (and which might not), and in how far the adaptation intervention is likely to be a source of conflict.

This article showed that "successful" CBA projects, by creating new abundances (e.g. income, water) may well serve as sources of new discrepancies and conflicts. The issue arises as a result of interventions taking a narrow and simplified account of communities whilst it is clear that climate change can only be understood in a context of a shared-resource system and competing claims. As a result of this simplification, selected target groups or "beneficiaries" are helped to strengthen their claims, contrary to the common good of all users and/or environmental interests.

To the extent that project interventions go hand in hand with conflicts, these are often described as unintended side-effects, or unintended outcome. This paper set out to explore the structural causes of such unintended conflicts arising as a result of adaptation interventions. It argues that whilst such conflicts are undoubtedly unintended, they are not unavoidable. Such conflicts arise firstly, because of the tendency of development actors to focus their attention on strengthening the resilience of targeted beneficiary group. Doing so simplifies a reality in which the same natural resources underpin, not one livelihood, many several, each with different definitions of sustainability. The paper argues that the tendency towards singularity is in part the result of limitations in the debate surrounding common-pool resources, which to date, both on the side who have argued that common-pool resource management is doomed to fail, and those who have rebutted that argument, have focussed on groups of homogenous livelihoods. In Africa's semi-arid and sub-humid belts, in contrast, high levels of both scarcity and seasonality have resulted in a high diversity of livelihoods, both across space and across time and, as a result, natural resources form the bases of a plethora of livelihoods. Using social capital theories, and especially in Narayan's hypothesis of the relationship between bridging social capital and governance frameworks [16], the paper illustrates how community-based approached to adaptation may result, depending also on the quality of the functionality of local governance frameworks, may result in either exclusion (latent conflict), potential for coping, social and economic well-being or conflict.

We conclude that, instead of targeting "communities" or other groups of "beneficiaries", the inter-connectedness of multiple (and at times competing) social groups (men and women, the elderly and youth, hunters, loggers, pastoralists and sedentary crop farmers etc.) in relation to the use and distribution of natural 
resources should be the point of departure for strengthening resilience and adaptive capacity. Importantly, we are not simply suggesting that such interconnectedness should be better appreciated by adaptation practitioners; they should be the point of departure, and form the focal point of interventionist actions that seek to strengthen adaptive capacity in rural contexts in the global south. Such an approach, in contrast to community-based or target group approaches, are better placed to anticipate and manage unintended impacts, and especially, the potential for conflict arising as a result of changes to the use and the distribution of natural resources between social groups, facilitated directly or indirectly by the CBA intervention itself.

\section{References}

[1] Adger, W. (2009) Social Capital, Collective Action, and Adaptation to Climate Change. Economic Geography, 79, 387-404.

https://doi.org/10.1111/j.1944-8287.2003.tb00220.x

[2] FRIDE (2015) Climate Change and State Fragility in the Sahel. https://www.iisd.org/sites/default/files/publications/climate-change-and-state-fragil ity-in-the-Sahel-fride.pdf

[3] Unger, N. (2015) Living on the Edge in a World of Changing Climate. https://blog.usaid.gov/2015/12/living-on-the-edge-in-a-world-of-changing-climate/

[4] Landscapes for People, Food and Nature (LPFN) (2015) Landscape Partnerships for Sustainable Development: Achieving the SDGs through Integrated Landscape Management a White Paper to Discuss the Benefits of Using ILM as a Key Means of Implementation of the Sustainable Development Goals Produced by the Landscapes for People, Food and Nature Initiative. Rep. Landscapes for People, Food and Nature, 15 Dec. 2015. Web. 26 Sept. 2016.

[5] Worldbank.org (2016) Climate Finance Overview. http://www.worldbank.org/en/topic/climatefinance/overview

[6] Wri.org (2016) Climate Finance World Resources Institute. http://www.wri.org/our-work/project/climate-finance

[7] Cannon, T. (2015) Why Do We Pretend There Is Community? Problems of Community Based-Adaptation (CBA) and Community Based Disaster Risk Reduction (CBDRR) [Blog] IDS Povertics.

http://vulnerabilityandpoverty.blogspot.nl/2014/04/why-do-we-pretend-there-is-co mmunity.html

[8] Reid, H., Alam, M., Berger, R., Cannon, T., Huq, S. and Milligan, A. (2009) Community-Based Adaptation: An Overview. In: Reid, H., Ed., Community-Based Adaptation to Climate Change, International Institute for Environment and Development, London, 11-38.

[9] Coleman, J. (1988) Social Capital in the Creation of Human Capital. American Journal of Sociology, 94, S95-S120. https://doi.org/10.1086/228943

[10] Pelling, M. and High, C. (2005) Understanding Adaptation: What Can Social Capital Offer Assessments of Adaptive Capacity? Global Environmental Change, 15, 308-319.

[11] Woolcock, M. and Narayan, D. (2000) Social Capital: Implications for Development Theory, Research and Policy. World Bank Research Observer, 15, 225-249.

https://doi.org/10.1093/wbro/15.2.225 
[12] Cannon, T. and Muller-Mahn, D. (2010) Vulnerability, Resilience and Development Discourses in Context of Climate Change. Natural Hazards, 55, 621-635. https://doi.org/10.1007/s11069-010-9499-4

[13] Portes, A. (1998) Social Capital: Its Origins and Applications in Modern Sociology. Annual Review of Sociology, 24, 1-24. https://doi.org/10.1146/annurev.soc.24.1.1

[14] Rubio, M. (1997) Perverse Social Capital-Some Evidence from Colombia. Journal of Economic Issues, 31, 805-816. https://doi.org/10.1080/00213624.1997.11505966

[15] Adger, W., Huq, S., Brown, K., Conway, D. and Hulme, M. (2003) Adaptation to Climate Change in the Developing World. Progress in Development Studies, 3, 179-195. https://doi.org/10.1191/1464993403ps060oa

[16] Narayan, D. (2002) Bond and Bridges: Social Capital and Poverty. In: Isham, J., Kelly, T. and Ramaswamy, S., Eds., Social Capital and Economic Development. Well-Being in Developing Countries, Edgar Elgar Publishing Ltd., Cheltenham, 58-82. https://doi.org/10.4337/9781781950388.00013

[17] Soeters, S.R. (2016) Building Bonds and Breaking Bridges: Community Based Adaptation (CBA) as a Source of Conflict in a Northern Ghanaian Landscape. In: Yaro, J.A. and Hesselberg, J., Eds., Adaptation to Climate Change and Variability in Rural West Africa, Springer, 102-120.

[18] Brooks, N., Grist, N. and Brown, K. (2009) Development Futures in the Context of Climate Change: Challenging the Present and Learning from the Past. Development Policy Review, 27, 741-765. https://doi.org/10.1111/j.1467-7679.2009.00468.x

[19] Bebbington, A. (1999) Capitals and Capabilities: A Framework for Analyzing Peasant Viability, Rural Livelihoods and Poverty. World Development, 27, 2021-2044.

[20] Bryceson, D. (2002) Multiplex Livelihoods in Rural Africa: Recasting the Terms and Conditions of Gainful Employment. The Journal of Modern African Studies, 40. https://doi.org/10.1017/S0022278X01003792

[21] Haan, L. and Zoomers, A. (2005) Exploring the Frontier of Livelihoods Research. Development and Change, 36, 27-47. https://doi.org/10.1111/j.0012-155X.2005.00401.x

[22] Grootaert, Narayan, J. and Woolcock (2004) Measuring Social Capital: An Integrated Questionnaire. World Bank Paper No. 18.

https://openknowledge.worldbank.org/bitstream/handle/10986/15033/281100PAPE R0Measuring0social0capital.pdf;sequence $=1$ https://doi.org/10.1596/0-8213-5661-5

[23] Hippolyt, P. (2015) Exclusion, Association and Violence: Trends and Triggers in Northern Ghana's Konkomba-Dagomba Wars. The African Anthroplogist, 10, 39-82.

[24] Reid, H., Haque, M., Kirkby, P., Roberts, E., Stubbings, A., Urquhart, P., Williams, C., Williams, M. and Zundel, T. (2015) "Community Based Adaptation: Measuring and Enhancing Effective Adaptation 9th International Conference 24-30 April 2015 Nairobi, Kenya”. Community Based Adaptation: Measuring and Enhancing Effective Adaptation. Nairobi: IIED, 2014. Web. 12 Mar. 2015.

[25] Conti, V. (2016) Community-Based Microfinance for Adaptation: Panacea for Inclusion at the Household Level, or Source of Gender Conflict? Master's Thesis, Universiteit Utrecht.

[26] Local Farmers (2014) Interviews with Farmers.

[27] Focus on Land in Africa (2011) Rise and Fall of Group Ranches in Kenya. Country Brief: Kenya. Focus on Land in Africa, Washington, 4.

http://www.focusonland.com/countries/rise-and-fall-of-group-ranches-in-kenya/ 
[28] Gartner, K. (2016) Liquid Assets, Institutions, Climate Change and Conflict: The Political Ecology of Water in Maji Moto Group Ranch, Narok South, Kenya A Case Study of Water-Related Conflict in a Maasai Community. MA, Universiteit Utrecht.

[29] Adano, W.R., Dietz, T., Witsenburg, K. and Zaal, F. (2012) Climate Change, Violent Conflict and Local Institutions in Kenya's Drylands. Journal of Peace Research, 49, 65-80. https://doi.org/10.1177/0022343311427344

[30] Hughes, L. (2013) Land Alienation and Contestation in Kenyan Maasailand. Conference Paper. http://hdl/handle.net/10535/8915

https://dlc.dlib.indiana.edu/dlc/bitstream/handle/10535/8915/HUGHES_0880.pdf?s equence $=1$

[31] Weesie, R. (2016) More Water, More Conflict? A Case Study on (Agro)-Pastoral Conflict and Cooperation over a Shared Water Resource Resulting from an Adaptation Intervention in Semi-Arid Kenya. MA, Universiteit Utrecht.

[32] Cosijnse, D. (2016) "Be Watchful When Roaming through the Forest, You Never Know What Danger or Resource You May Stumble Upon": An Analysis of the Use and Management of Tiogo Forest through a Social Capital Lens. MA, Universiteit Utrecht.

[33] Wardell, A. and Reenberg, A. (2006) Framing Field Expansion Strategies in the Savanna Biome-Land Use and Land Cover Dynamics in and around Tiogo Forest Reserve, Burkina Faso. In: Mistry, J. and Berardi, A., Eds., Savannas and Dry Forests. Linking People with Nature, Ashgate Publishers Ltd., Aldershot, 19-52.

[34] Ouedraogo, B. (2014) To Limit Forest Loss, Burkina Faso Brings Communities into Decision Making. Thomson Reuters Foundation, 17 June 2014. http://news.trust.org//item/20140617153754-d9zb2/?source=fiHeadlineStory 